$17^{\text {th }}$ International Congress of Metrology, 03001 (2015)

DOI: $10.1051 /$ metrology / 201503001

(C) Owned by the authors, published by EDP Sciences, 2015

\title{
Evaluation of Vortex flow meters
}

\author{
Isabelle CARE $1, a$, José VEAU² \\ ${ }^{1}$ CETIAT, Domaine scientifique de la Doua, 25 avenue des Arts, 69100 Villeurbanne, France \\ ${ }^{2} E D F R \& D$, Département STEP, 6 quai Watier, BP 49, 78401 CHATOU, France
}

\begin{abstract}
Résumé. Les débitmètres à effet Vortex sont utilisés dans l'industrie pour des écoulements liquide, gazeux ou de vapeur. Pour répondre aux interrogations de ses membres sur les performances réelles des instruments, l'EXERA (Association d'utilisateurs d'instruments de mesure, de contrôle et d'automation) a conduit un programme d'évaluation sur cinq débitmètres à effet Vortex disponibles sur le marché français. Le programme d'essais inclut l'évaluation des performances métrologiques avec de l'eau à $20^{\circ} \mathrm{C}$ et de l'air à 6 bar abs. Les résultats sont comparés aux performances annoncées par les constructeurs. Afin d'évaluer l'effet de quelques conditions qui pourraient se rencontrer en conditions réelles, sur site, des essais complémentaires ont été menés. Certaines de ces conditions d'essais sont, intentionnellement, en dehors des conditions d'utilisation préconisées par les constructeurs. L'influence de vibrations mécaniques proches de la fréquence des tourbillons est évaluée ainsi que l'influence du profil de vitesse en amont du débitmètre par la présence de coudes (simple et double non coplanaires) à une distance réduite. Pour finir, l'influence d'un dépôt sur l'arête vive du barreau des débitmètres a également été explorée. Les essais réalisés permettent de statuer sur les performances des débitmètres dans ces conditions particulières de mesure.
\end{abstract}

\section{Introduction}

A Vortex flow meter consists of a bluff body placed in a pipe section. When the Reynolds number is high enough, vortices are created downstream the bluff body. These vortices develop in, what is called, a von Karman vortex street.

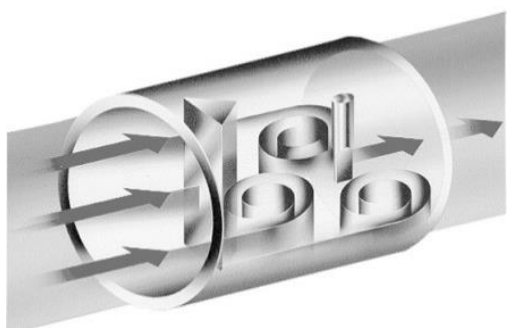

Figure 1 - Vortices downstream the bluff body of a vortex flow meter

The frequency of the vortex shedding, $f$, is related to the mean velocity of the fluid, $U$, and the width of the bluff body, D, through the dimensionless Strouhal number, St, according to the following relation:

$$
S t=\frac{D \times f}{U}
$$

For a wide Reynolds number range, Strouhal number is constant as shown on Figure 2 below:

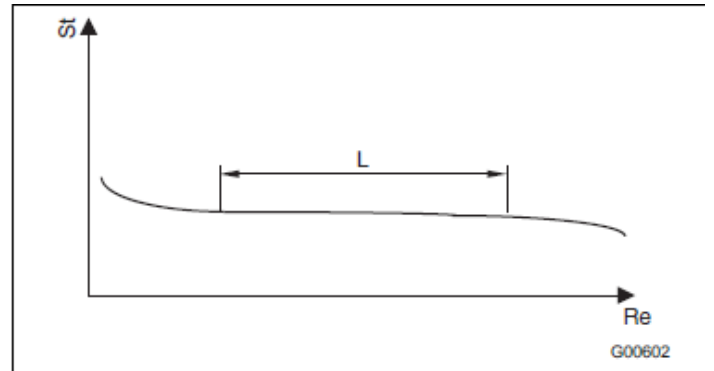

Figure 2 - Strouhal number, St, against Reynolds number, Re

The mean velocity of the fluid in the pipe section, $U$, can then be estimated through a measurement of the vortex frequency. Taking into account an assumption of a developed turbulent flow profile in the pipe, the volume flow rate, $\mathrm{Q}$, is deduced from this estimate of the mean velocity.

$$
Q=k \times U \times S
$$

where $\mathrm{S}$ is the section of the pipe and $\mathrm{k}$ a correction coefficient for the velocity profile.

Vortex flow meters are widely used in industry either for gas, liquid or steam flows. Since, according to Eq (1), the vortex frequency is independent to the nature of fluid, these flow meters are often calibrated by manufacturers only with water for some economical and technical reasons.

As users, we can wonder if the behavior of a vortex flow meter is strictly the same whatever the flowing fluid is. It is the reason why EXERA has decided to evaluate some of the commercialized vortex flow meters.

EXERA is a french association of companies using measuring instruments and exchanging on their

\footnotetext{
${ }^{\mathrm{a}}$ Corresponding author : isabelle.care@cetiat.fr
} 
measurement experiences. The members have built a test program to evaluate the performance of the instruments in some conditions which could be met on site and not only in ideal conditions as reported in the manufacturers' specifications sheets.

\section{Evaluated flow meters and test program}

The vortex flow meters were lent by the manufacturers who approved the proposed test program. Three manufacturers accepted to participate to the test program and five different meter models were evaluated.

Table 1 - Evaluated flow meters

\begin{tabular}{|c|c|}
\hline Manufacturer & Model \\
\hline \multirow{2}{*}{$\mathrm{ABB}$} & FSV 430 \\
\hline & FSS 4-30 \\
\hline \multirow{2}{*}{ GE SENSING } & $\underline{\text { PanaFlow MV80 }}$ \\
\hline & PanaFlow MV82 \\
\hline YOKOGAWA & $\frac{\text { Digital YewFlo }}{\text { DY50 }}$ \\
\hline
\end{tabular}

The tested models were those adapted to a DN50 pipe diameter.

With additional sensors of pressure and temperature, vortex flow meters are able to measure directly mass flow rate. It is the case of some of the tested flow meters and in particular of the flow meter B. It explains why some results are presented in mass flow units in the case of tests performed with air.

First, the behavior of the meters in ideal conditions was checked using both water and air as fluid. The ideal conditions are defined by each manufacturer mainly in terms of minimum upstream and downstream straight lengths. The measured performances were compared to the manufacturer's specifications.

Then, the meters were tested in different conditions far from ideal conditions since, on site, the ideal conditions are sometimes not met. These test conditions were the following:

- influence of shorter upstream straight lengths in the case of two different types of disturbances (one simple bend, two noncoplanar bends)

- influence of mechanical vibrations

- erosion of the sharp edge of the bluff body

The reason of the choice of each of these conditions is explained further in this paper. These additional tests were all performed in air.

The results are presented in this paper anonymously for three of the five tested flow meters (the three models underlined in Table 1). Detailed results of all flow meters are available for EXERA members in reports [1] to [5].

Tests were performed at CETIAT (France) in the COFRAC accredited gas and liquid flow laboratories.
Furthermore, the liquid (water) flow lab is recognized as the national reference lab in the field.

The gas flow reference flow rate was measured using a set of critical nozzles while the liquid flow reference flow rate was measured using a gravimetric method.

\section{Results}

\subsection{Metrological performances}

The metrological performances are evaluated in water and in air at the following conditions:

- Flow rates: Qmin, 0.25Qmax, 0.5Qmax, 0.75Qmax, Qmax

- upstream/downstream straight lengths: 30D/10D

- Water temperature: $20^{\circ} \mathrm{C}$

- Air pressure: 6 bar abs.

When possible the error of the instrument is drawn against Reynolds number to put on the same graph the results obtained in water and those obtained in air. The manufacturer's calibration curve is also added when available as well as the manufacturer's specifications.

The following notations are used below:

- qvr (resp. qmr), reference volume (resp. mass) flow rate (measured by the calibration test rig)

- $\quad$ qvd (resp. qmd), volume (resp. mass) flow rate measured by the instrument under test. This value is calculated using either the current output or the pulses output of the instrument

Results are presented below for the three selected flow meters.
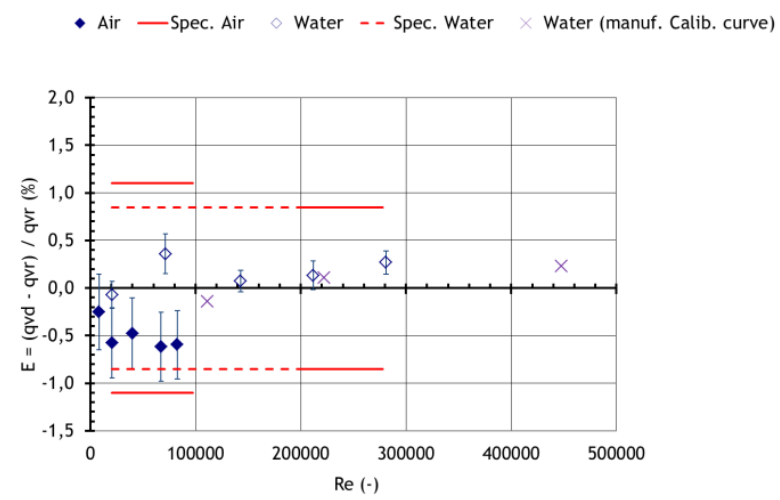

Figure 3 - Metrological performances of flow meter A - Air - Water - Spec. Air - - Spec. Water + Manuf. Calibration curve (Water)

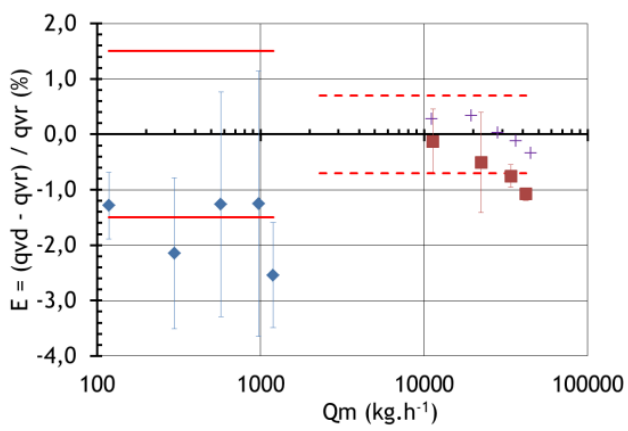

Figure 4 - Metrological performances of flow meter B 


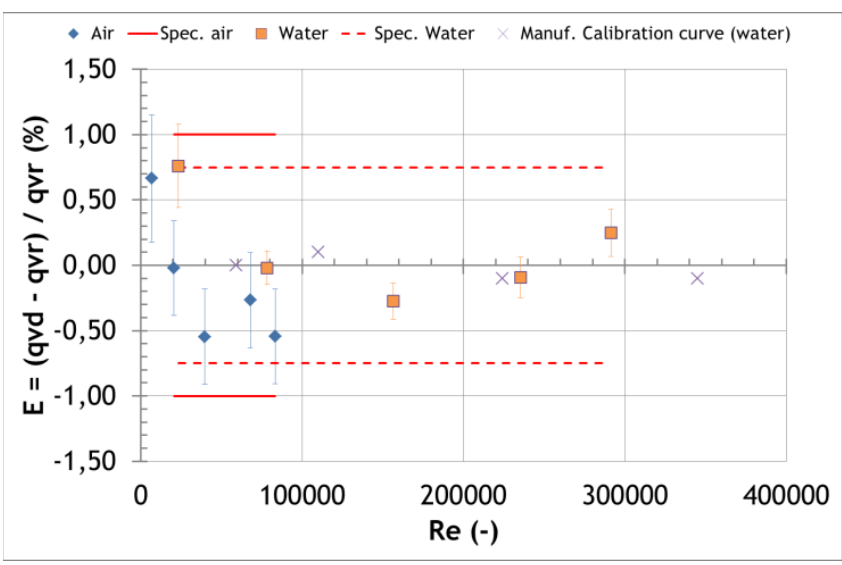

Figure 5 - Metrological performances of flow meter C

Flow meters $\mathrm{A}$ and $\mathrm{C}$ measure a true volume flow rate. It is then possible to draw the error curve against the Reynolds number, Re, defined as:

$$
R e=\frac{U \times D}{v}
$$

where $v$ is the kinematic viscosity of the fluid.

With additional measurements of pressure and temperature integrated in flow meter $B$ the mass flow rate for gas is directly measured. In the case of this flow meter, Reynolds number cannot be estimated because the true velocity is not known. It is why, on Figure 2, the error is drawn against the mass flow rate.

If a deviation is observed between the calibrations with water and with air, results are still in the manufacturers' specifications for the flow meters A and C.

\subsection{Influence of shortened upstream straight lengths}

In real conditions, it is sometimes difficult to reach the minimum straight lengths specified by the manufacturers. It is then interested to have an idea of the behavior of the flow meters in such conditions.

If the velocity profile is distorted because of upstream disturbances, the error on the mean velocity might occur. To estimate the influence of shortened straight lengths, tests were performed with some disturbances at different distances upstream the flow meter. The disturbances which have been used are a single bend and a double non coplanar bend at different distances, according Table 2, below.

Table 2 - Experimental conditions

\begin{tabular}{|c|c|c|}
\hline Disturbances & $\begin{array}{c}\text { Upstream } \\
\text { distance }\end{array}$ & $\begin{array}{c}\text { Downstream } \\
\text { distance }\end{array}$ \\
\hline & $10 \mathrm{D}$ & $10 \mathrm{D}$ \\
Single bend & $20 \mathrm{D}$ & $10 \mathrm{D}$ \\
& $30 \mathrm{D}$ & $10 \mathrm{D}$ \\
\hline \multirow{3}{*}{$\begin{array}{c}\text { Double non } \\
\text { coplanar bend }\end{array}$} & $10 \mathrm{D}$ & $10 \mathrm{D}$ \\
& $30 \mathrm{D}$ & $10 \mathrm{D}$ \\
\end{tabular}

Some of these conditions are out of the minimum distances specified by the manufacturers. These minimum distances are different from a manufacturer to another one and vary from $10 \mathrm{D}$ to $20 \mathrm{D}$ for a single bend and from 20D to 40D for a double non coplanar bend.
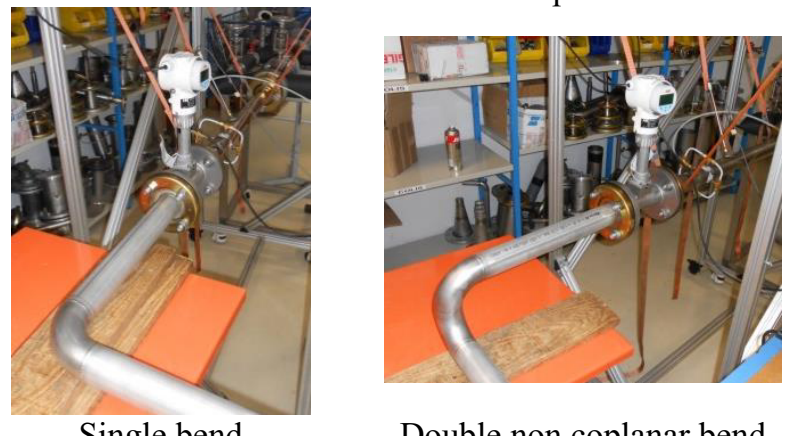

Single bend

Figure 6 - Photos of the disturbances

The influence of upstream disturbances was evaluated in air at a pressure of 6 bar abs.. Compared to water, dynamic viscosity of air is much lower and, as a consequence, the influence of upstream disturbances should be higher and more interesting to estimate.

The results are presented below first for a single bend and then for a double non coplanar bend.

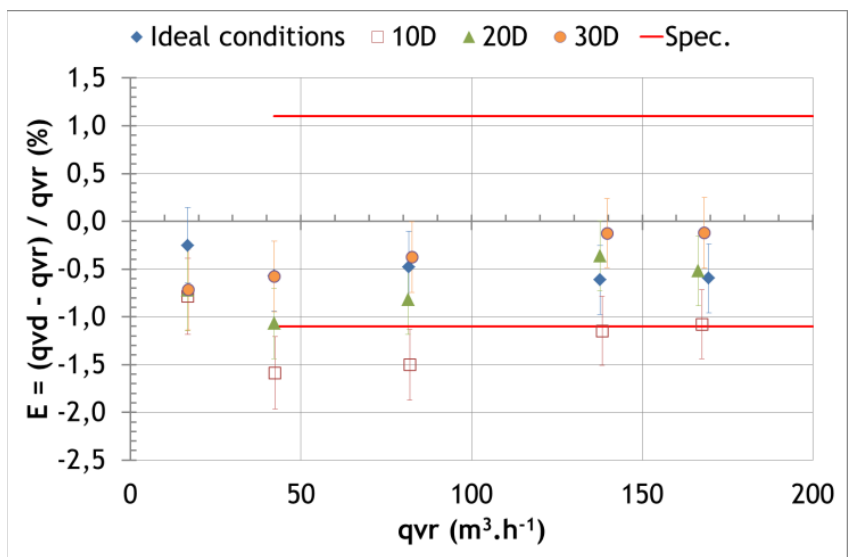

Figure 7 - Influence of an upstream single bend on flow meter A

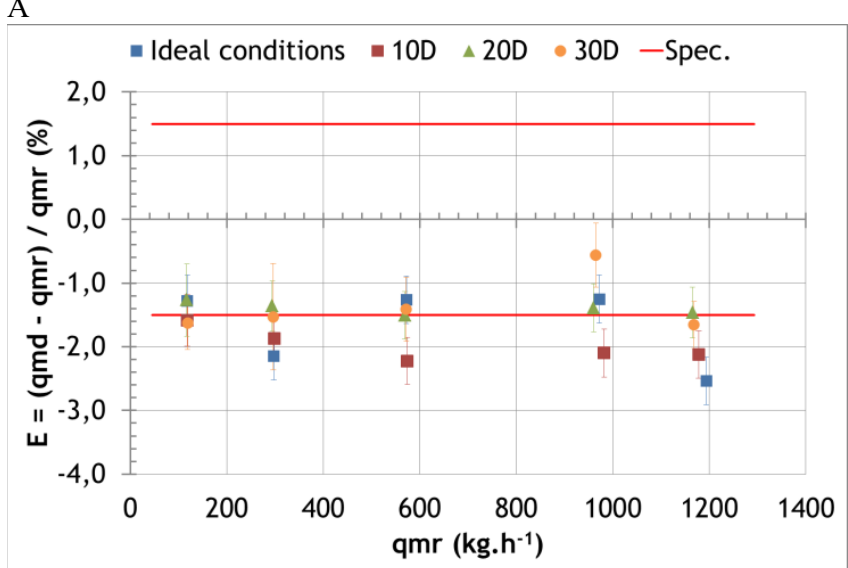

Figure 8 - Influence of an upstream single bend on flow meter B 


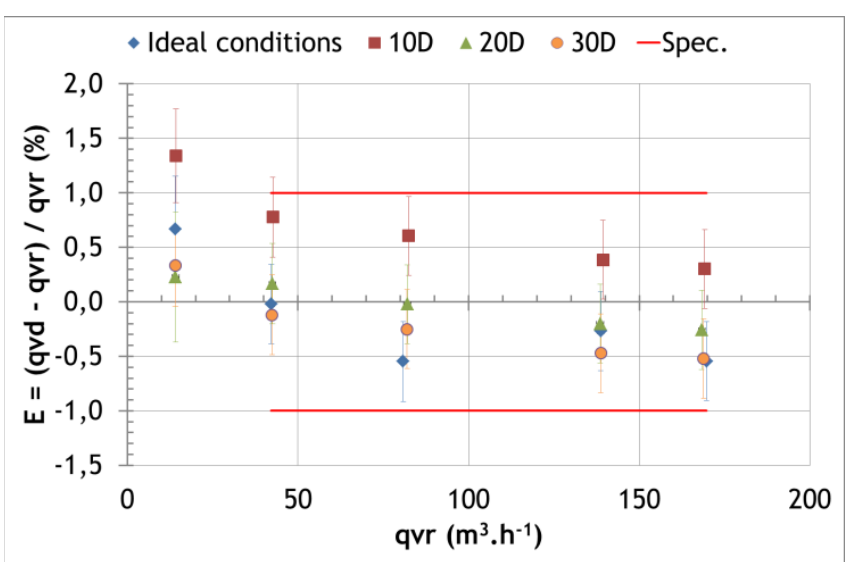

Figure 9 - Influence of an upstream single bend on flow meter $\mathrm{C}$

On the figures above, when the mark is full, the upstream condition meets the minimum upstream distance specified by the manufacturer. When it is empty, it doesn't meet. On these figures, in the case of a single bend, the upstream distance seems to have an influence on the response of the flow meters $\mathrm{A}$ and $\mathrm{C}$. The manufacturer specifications are met when the minimum upstream distance condition is fulfilled. In the case of flow meter $B$, the upstream distance seems to have no specific influence.

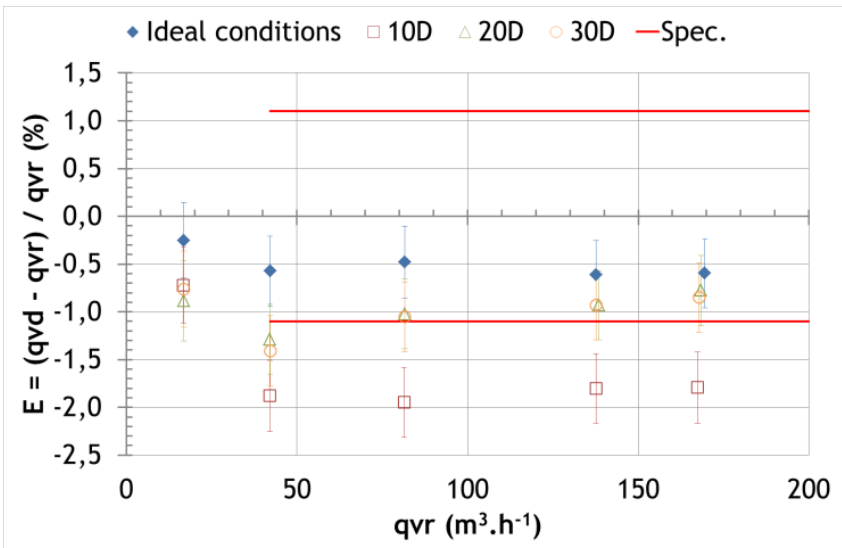

Figure 10 - Influence of an upstream double non coplanar bend on flow meter $\mathrm{A}$

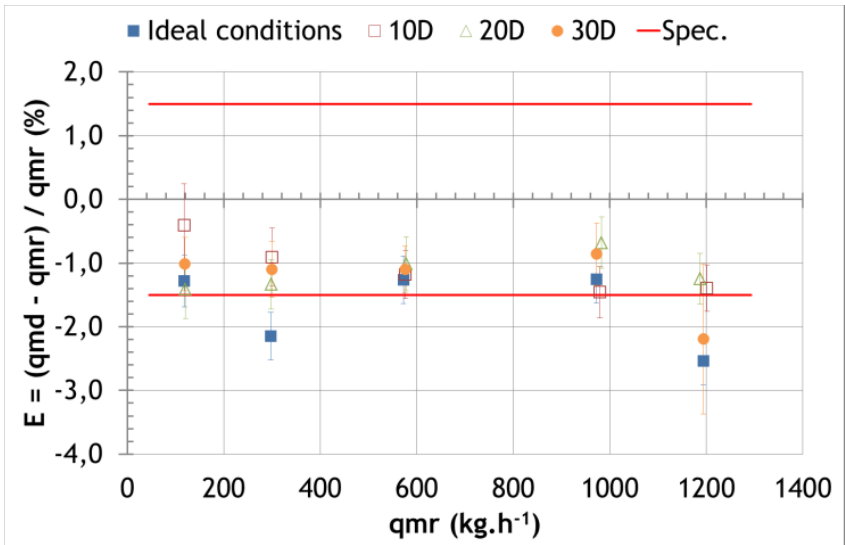

Figure 11 - Influence of an upstream double non coplanar bend on flow meter B

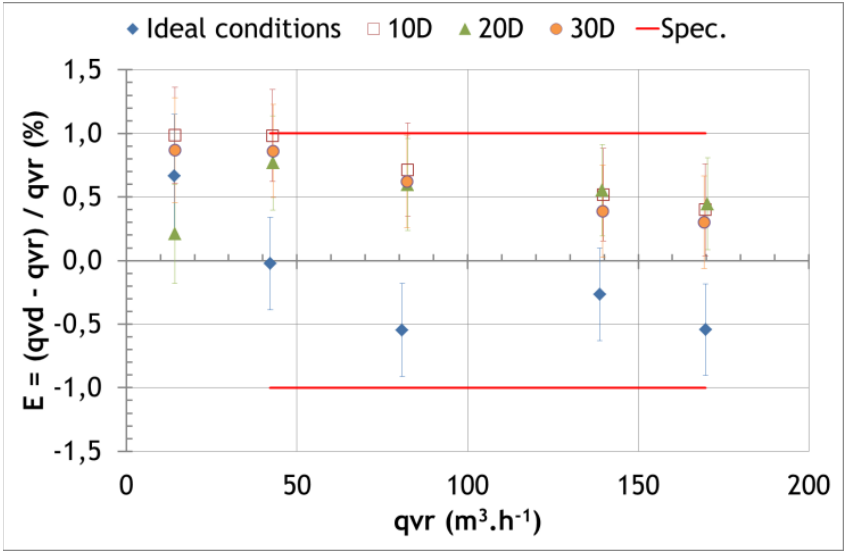

Figure 12 - Influence of an upstream double non coplanar bend on flow meter $\mathrm{C}$

In the case of a double non coplanar bend, the minimum upstream distance specified by the manufacturer is higher. An increase of the upstream distance has no significant effect on the response of the flow meter.

\subsection{Influence of vibrations}

The working principle of a vortex flow meter is based on the measurement of the frequency of vortices. We could then wonder if mechanical vibrations of the pipe could generate artificial vortices and measurement errors.

The test program consists in generating artificial vibrations on the flow meter at different frequencies at a flow rate of 0.75 Qmax at 6 bar abs. with air as flowing fluid and in measuring the response of the flow meter in these conditions. The response of the flow meter is also recorded without flow.

The mechanical vibrations are generated using a vibrating pot as shown on the figure below.

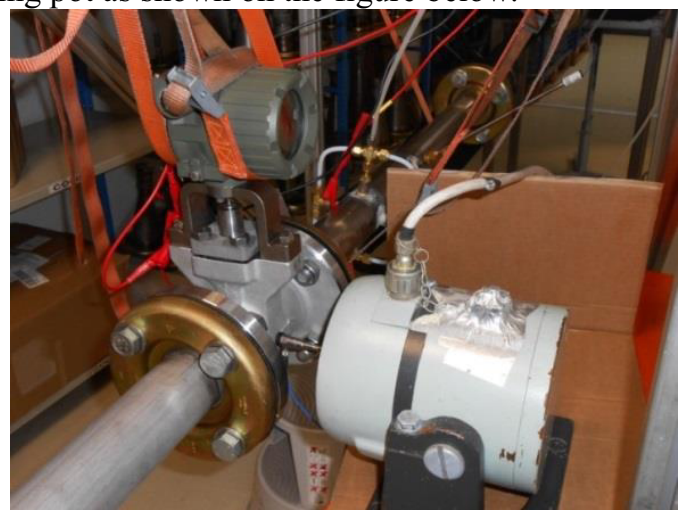

Figure 13 - Vibrating pot placed on a flow meter

The chosen vibrations, for an acceleration of $1 \mathrm{~g}$ are:

- $50 \mathrm{~Hz}$ (the frequency of the electrical network)

- the frequency of the vortices at the chosen flow rate and frequencies closed to this one

- the double and the half of this frequency

The results of these tests, for the three flow meters are presented below. 


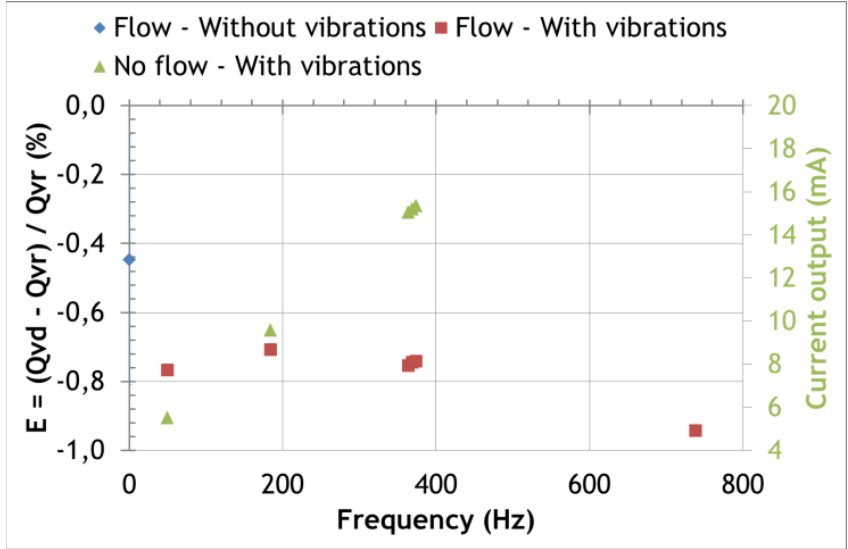

Figure 14 - Influence of mechanical vibrations on flow meter A

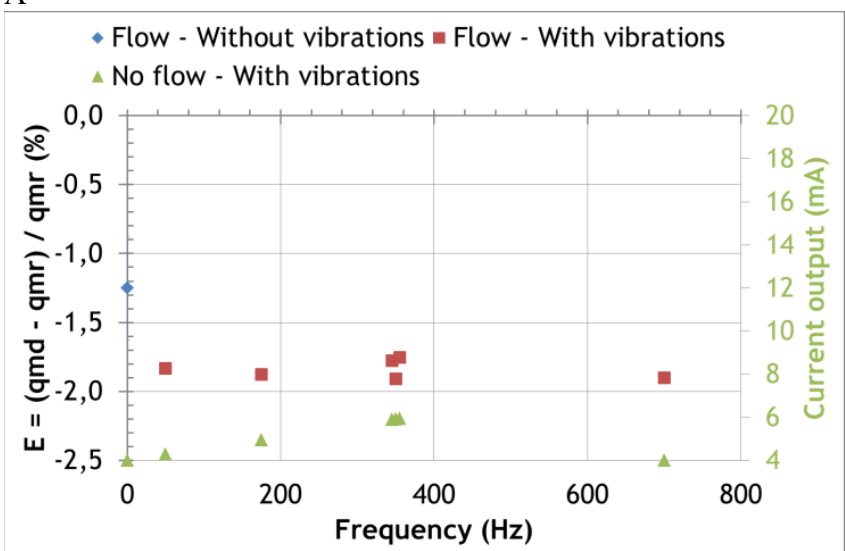

Figure 15 - Influence of mechanical vibrations on flow meter B

This test has not been performed for the flow meter C. It can be observed that the mechanical vibrations modify the behavior of the both flow meters in case of flow with no particular difference according to the frequency.

When there is no flow but vibrations, an artificial flow rate is measured by the flow meter since the current output is different from $4 \mathrm{~mA}$ and in the case of the flow meter may really vary.

\subsection{Influence of the erosion of the sharp edge of the bluff body}

Vortices are generated at the sharp edge of the bluff body of a vortex flow meter. In real conditions, fluid is sometimes polluted by particles which could cause an erosion of this edge.

The objective of this part of the test program is to evaluate the impact of this erosion on the measurement of the flow meter. Erosion was simulated adding a thin layer of varnish on the edge as shown on the figure below.

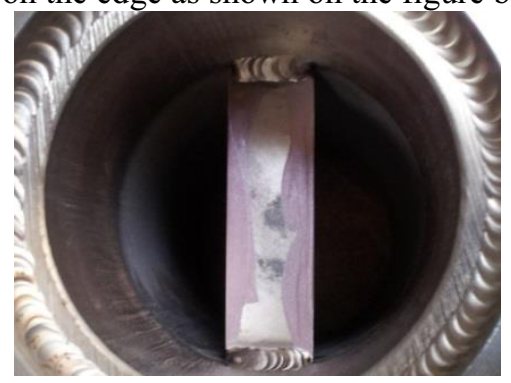

Figure 16 - Varnish deposit on the edge of the bluff body
The thickness of this deposit varies between $100 \mu \mathrm{m}$ and $200 \mu \mathrm{m}$.

The flow meters are tested in ideal conditions with air at 6 bar abs. The results obtained are presented below and compared with the initial metrological performances.

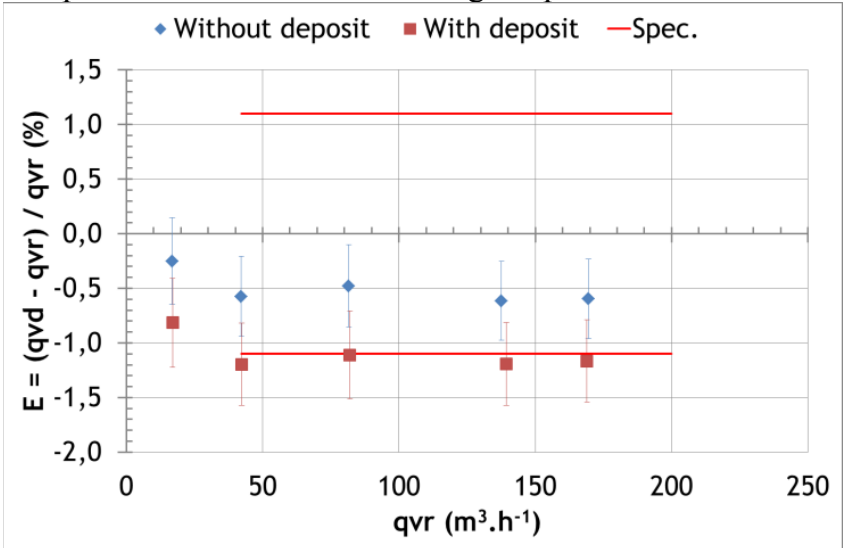

Figure 17 - Influence of the deposit on the sharp edge of the bluff body of flow meter A

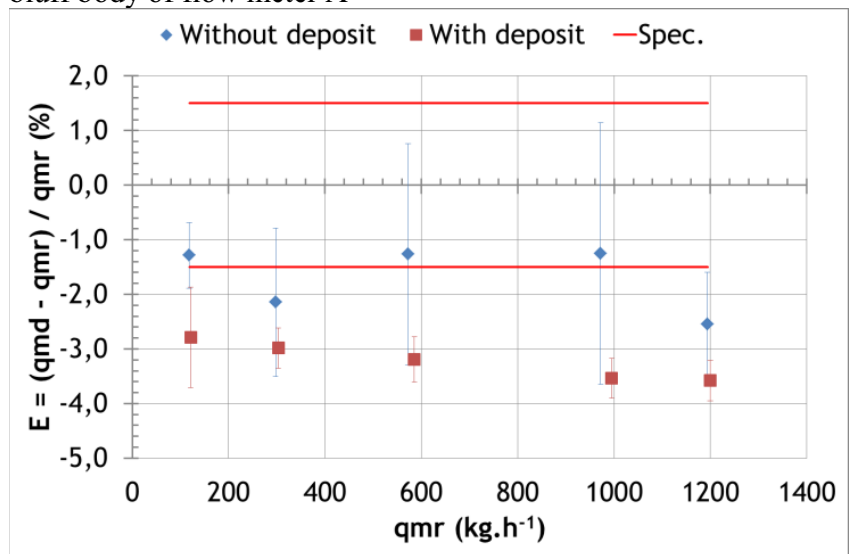

Figure 18 - Influence of the erosion of the sharp edge of the bluff body of flow meter B

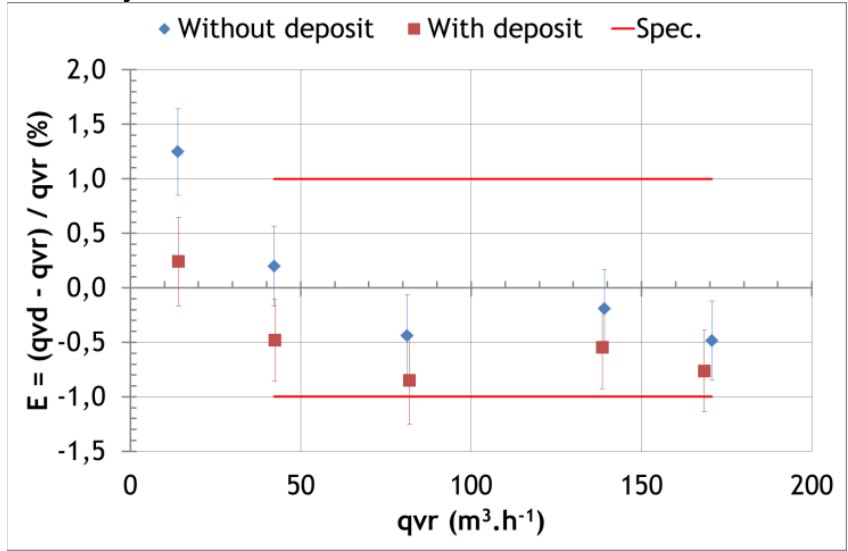

Figure 19 - Influence of the erosion of the sharp edge of the bluff body of flow meter $\mathrm{C}$

In all the cases, the deposit shifts the response of the flow meter in the same direction. It seems it generates fewer vortices, probably because the edge is smoother. We can then assume that, in case of erosion of the edge due to particles in the fluid, the flow meter would underestimate the flow rate. 


\section{Conclusions}

Vortex flow meters, available on the market, were evaluated in different conditions. A comparison with manufacturers' specifications was performed with air and water as flowing fluids. Even if the behavior is different with air and water, the flow meters' response is mainly within the manufacturers' specifications.

The flow meters were then evaluated in some extreme conditions which could occur on site. The tested conditions were shortened upstream straight lengths, mechanical vibrations and deposit on the edge of the bluff body. If shortened straight lengths have a limited influence on the response of the flow meters, we have observed a significant deviation of the response of all the flow meters in the case of mechanical vibrations and deposit on the edge of the bluff body.

\section{Thanks}

We would like to thank EXERA and its members to have initiated this program of tests and the manufacturers (ABB, GE Sensing and Yokogawa) for their financial and technical support.

\section{References}

1. I. Caré, EXERA, Débitmètre à effet Vortex, $A B B$ FSV 4-30 DN50, E6025X14 (2014)

2. I. Caré, EXERA, Débitmètre à effet Swirl, $A B B$ Swirlmaster FSS 4-30 DN50, E6026X14 (2014)

3. I. Caré, EXERA, Débitmètre à effet Vortex, GE SENSING PanaFlow MV80, E6022X14 (2014)

4. I. Caré, EXERA, Débitmètre à effet Vortex, GE SENSING PanaFlow MV82, E6023X14 (2014)

5. I. Caré, EXERA, Débitmètre à effet Vortex, Digital Yewflo DY50, E6024X14 (2014) 